\title{
A case-control study of risk factors for asthma in New Zealand children
}

\author{
Abstract \\ Objective: As in other English-speaking \\ countries, asthma is a major and increasing \\ health problem in New Zealand. This study \\ examined the risk factors for asthma in \\ children aged 7-9.
}

Methods: Cases and controls were randomly selected from participants in the Wellington arm of the International Study of Asthma and Allergies in Childhood (ISAAC). Cases were children with a previous diagnosis of asthma and current medication use $(n=233)$, and controls were children with no history of wheezing and no diagnosis of asthma ( $n=241)$.

Results: After controlling for confounders, factors significantly associated with asthma were maternal $(\mathrm{OR}=3.36,95 \% \mathrm{Cl} 1.88$ $5.99)$ and paternal asthma (OR=2.67, 95\% $\mathrm{Cl}$ 1.42-5.02), and male sex (OR=1.81, $95 \% \mathrm{Cl} 1.17-2.81$ ). Children from social classes 5 and 6 or with unemployed parents (OR=2.32, 95\% Cl 1.22-4.44) were significantly more likely to have asthma than children in social classes 1 and 2 . There was no significant association between having polio vaccination (OR=2.48, 95\% Cl 0.83-7.41), hepatitis B vaccination ( $\mathrm{OR}=0.66,95 \% \mathrm{Cl} 0.42-1.04$ ) or measles/mumps/rubella vaccination (OR=1.43, 95\% Cl 0.85-2.41) and asthma. Conclusions: This study has confirmed the associations of family history and lower socio-economic status with current asthma in 7-9 year old children. The role of vaccinations requires further research.

(Aust N Z J Public Health 2001; 25: 44-9)

\section{Kristin Wickens, Julian Crane, Trudi Kemp, Simon Lewis, Wendyl D'Souza, Gillian Sawyer, Louise Stone, Sarah Tohill, Jo Kennedy, Tania Slater, Natalie Rains and Neil Pearce}

Wellington Asthma Research Group, Wellington School of Medicine, New Zealand

A $\mathrm{s}$ in other English-speaking countries, asthma is a major health problem in New Zealand with $26 \%$ of adults ${ }^{1}$ and $30 \%$ of $13-14$ year olds ${ }^{2}$ reporting wheezing in the past 12 months. There is evidence also that prevalence is increasing. ${ }^{3,4}$ Prevalence studies in New Zealand ${ }^{3,5,6}$ have identified various risk factors for childhood asthma, including male sex, ${ }^{5,7}$ parental ${ }^{3,5,6}$ or sibling asthma, ${ }^{6}$ or having eczema during the first year of life. ${ }^{6}$ However, there have also been inconsistent findings among these studies, including reports that paternal asthma ${ }^{5}$ and parental eczema ${ }^{6}$ are not significantly related to asthma in the child, and that the influence of parental asthma may depend on a child's gender. ${ }^{8}$

More recently, a role for vaccination in promoting allergic sensitisation has been proposed. ${ }^{9-11}$ It has been hypothesised that intracellular infections in early life promote a predominantly $\mathrm{TH} 1$ response, rather than the TH2 response important in the development of atopy. ${ }^{10}$ In this context, vaccinations may contribute towards sensitisation because they reduce clinical infection. Alternatively, they may directly promote the development of sensitisation. ${ }^{11}$ Certainly, pertussis vaccination has been found to act as an adjuvant for antigen-specific responses in laboratory animals. ${ }^{12}$ There are, however, few epidemiological studies that have examined the role of vaccinations in the development of atopy or asthma. ${ }^{9,13-17}$ For these reasons, we conducted a case-control study of asthma in childhood and report here the findings for demographic factors and vaccinations.

\section{Methods}

The case-control study was based on the Wellington, New Zealand, arm of the International Study of Asthma and Allergies in Children (ISAAC), which was a study of all children aged 6-7 and 13-14 from a random selection of schools. There were 3,318 children aged 6-7 years included in the Wellington survey, a response rate of $92 \% .{ }^{18}$ For the current study, potential cases and potential controls were each randomly selected from these 3,318 children.

\section{Recruitment of study subjects}

Potential cases and potential controls were selected from the 3,318 ISAAC Wellington participants in the younger age group, by then aged 7-9 (mean age 8.3). The 781 children who reported wheezing or whistling in the chest in the past 12 months and reported ever having had asthma constituted the sampling frame from which 399 potential cases were selected at random. In order to limit the cases to children with current asthma, screening questions to the parents further restricted the cases to children with diagnosed asthma who had used asthma medication in the past 12 months.

The 2,113 children who had never had wheezing or whistling in the chest and who had never had asthma comprised the sampling frame from which the 398 potential
Submitted: January 2000

Revision requested: October 2000

Accepted: December 2000

\section{Correspondence to:}

Kristin Wickens, Wellington Asthma Research Group, Wellington School of Medicine, PO Box 7343, Wellington South, New Zealand.

Fax: +64 4389 5427; e-mail: kwickens@kokako.wnmeds.ac.nz 
controls were selected. Further screening questions ensured that these children had never had wheezing or whistling in the chest or a doctor's diagnosis of asthma.

All schools co-operated in distributing to parents an information sheet and a reply form asking for addresses and phone numbers. When children had moved to another school within Wellington since their participation in ISAAC, this school was invited to co-operate in the study. When children had moved outside Wellington they were considered ineligible.

\section{Collection of exposure information}

Parents who returned reply forms were contacted and asked the additional screening questions that determined the final case or control status of the child. Appointments were made with eligible respondents to visit them in their homes. When a birth parent lived separately, permission was asked from the responding parent to contact the absent parent.

Questionnaires recorded information about a variety of demographic and other possible risk factors for asthma. These included gender and ethnicity of the child and the occupations of up to two parents or caregivers in the household. The New Zealand Elley Irving scale of socio-economic status ${ }^{19}$ was used to assign social class codes 1 (highest) to 6 (lowest) according to the occupation of the parent or caregiver with the higher income. This classification groups occupations according to the mean levels of education and income. Although households without a parent or caregiver in employment are excluded from the classification, we included them as a separate category in the analysis. Information was also collected on current smoking in the home and smoking during the first year of life, other atopic diseases in the sampled child and in birth parents and siblings. Each birth parent was separately asked about their own history, with the mother additionally asked to supply information about previous births, length of gestation, birth weight and infant feeding of the selected child. This information was also collected from birth parents who lived separately and had agreed to participate.

Approximately one year after the main interviews, vaccination histories were collected blind from the medical notes of the child's general practitioner (GP), after permission had been granted by the parents. When the current GP did not have the vaccination history, previous GPs were visited. GPs outside Wellington were written to and asked to complete a vaccination history questionnaire. If notes were not available after contacting all doctors, parents were contacted again and asked to complete a vaccination

Table 1: Response rates of cases and controls.

\begin{tabular}{|c|c|c|}
\hline & Cases & Controls \\
\hline ISAAC sample & 399 & 398 \\
\hline Ineligibles & 97 & 50 \\
\hline Eligible sample & $302(100 \%)$ & $348(100 \%)$ \\
\hline Refused & $44 \quad(15 \%)$ & $69(20 \%)$ \\
\hline No response & $25 \quad(8 \%)$ & $38(11 \%)$ \\
\hline Respondents & $233 \quad(77 \%)$ & 241 (69\%) \\
\hline
\end{tabular}

history from their child's Health and Development Record. Vaccination questionnaires were coded according to whether records (either the child's GP notes or Health and Development Record) completely covered the period from birth to the survey date, partly covered this period or there were no records available. Thus, data that was not based on records was able to be excluded from the analyses.

\section{Statistical analysis}

Data analysis was conducted using SAS. Odds ratios and 95\% confidence intervals (CI) were estimated using the MantelHaenszel method ${ }^{20}$ for univariate analysis and unconditional multiple logistic regression ${ }^{21}$ to adjust for potential confounders.

\section{Results}

Of the 399 potential cases selected from the ISAAC survey, 97 were ineligible: eight had never had a doctor's diagnosis of asthma; 60 had not used medication in the past 12 months; 24 had moved away from Wellington; four had moved but their whereabouts was unknown and the reason for ineligibility was not recorded for one potential case. Of the 398 potential controls, 50 were ineligible: 14 had reported wheezing or whistling in the chest at sometime in the past; five had had a doctor's diagnosis of asthma; 29 had moved away from Wellington; and two had moved but their whereabouts was unknown. Among the eligible population, 233 (77\%) cases and $241(69 \%)$ controls participated in the study (see Table 1).

For the vaccination arm of the study, 11 of the 233 participating cases had moved and could not be traced and two cases declined to provide the name of the child's current doctor. Similarly, five of the 241 controls had moved and could not be traced, one control refused and four controls declined to provide the name of the child's current doctor. The children of parents who did not supply doctor's names were excluded from the vaccination analyses. Among those included in the main analysis, there were 194 cases and 204 controls with records available since birth, 17 cases and 16 controls where records were available for only some of the period, and 9 cases and 11 controls where no records were located.

Table 2 shows that male sex was associated with twice the risk of asthma and having parents in social classes 5 or 6 , or unemployed, was associated with a small increased risk for asthma, with some evidence of a dose response. Stratification of the data by ethnicity showed that the effect of social class on asthma was independent of ethnicity.

Table 3 shows that maternal asthma, eczema and hayfever, paternal asthma, eczema and hayfever and sibling asthma were factors significantly associated with asthma. Either parent having asthma was also strongly associated with asthma in the child $(\mathrm{OR}=3.79,95 \% \mathrm{CI} 2.57-5.61)$, and this was stronger for boys $(\mathrm{OR}=4.11,95 \% \mathrm{CI} 2.39-7.08)$ than girls $(\mathrm{OR}=3.11,95 \% \mathrm{CI} 1.74$ 5.56). When both parents had asthma, the odds ratio increased to 9.95 (95\% CI 2.84-34.88) compared with neither parent having 
Table 2: Odds ratios and $95 \%$ confidence intervals for the association between asthma in New Zealand children and demographic characteristics.

\begin{tabular}{|c|c|c|c|c|}
\hline & $\begin{array}{l}\text { Cases } \\
(n=233)\end{array}$ & $\begin{array}{l}\text { Controls } \\
(n=241)\end{array}$ & OR & $95 \% \mathrm{Cl}$ \\
\hline \multicolumn{5}{|l|}{ Sex } \\
\hline Female & 91 & 134 & $1.00^{\mathrm{a}}$ & \\
\hline Male & 142 & 107 & $1.95^{\star}$ & $1.36-2.81$ \\
\hline \multicolumn{5}{|l|}{ Ethnicity } \\
\hline European/Other & 177 & 187 & $1.00^{\mathrm{a}}$ & \\
\hline Maori & 36 & 31 & 1.23 & $0.73-2.07$ \\
\hline Pacific Island & 20 & 23 & 0.92 & $0.49-1.73$ \\
\hline \multicolumn{5}{|l|}{ Social Class } \\
\hline $1 \& 2$ & 106 & 118 & $1.00^{\mathrm{a}}$ & \\
\hline 3 & 44 & 52 & 0.94 & $0.58-1.52$ \\
\hline 4 & 30 & 28 & 1.19 & $0.67-2.13$ \\
\hline $5 \& 6$, unemployed & d 53 & 43 & 1.36 & $0.86-2.13$ \\
\hline $\begin{array}{l}\text { Notes: } \\
\text { (a) Reference category. } \\
{ }^{*} p<0.001\end{array}$ & & & & \\
\hline
\end{tabular}

Table 3: Odds ratios and $95 \%$ confidence intervals for the association between asthma in New Zealand children and atopic disease in siblings and parents.

\begin{tabular}{|c|c|c|c|c|}
\hline & $\begin{array}{c}\text { Cases } \\
(n=233)\end{array}$ & $\begin{array}{c}\text { Controls } \\
(n=241)\end{array}$ & OR & $95 \% \mathrm{Cl}$ \\
\hline \multicolumn{5}{|c|}{ Sibling asthma ${ }^{a}$} \\
\hline Yes & 123 & 81 & $2.78^{\star \star \star}$ & $1.88-4.11$ \\
\hline No & 76 & 139 & $1.00^{b}$ & \\
\hline \multicolumn{5}{|c|}{ Sibling eczema ${ }^{a}$} \\
\hline Yes & 109 & 99 & 1.44 & $0.98-2.12$ \\
\hline No & 91 & 119 & $1.00^{b}$ & \\
\hline \multicolumn{5}{|c|}{ Sibling hayfever ${ }^{\mathrm{a}}$} \\
\hline Yes & 60 & 54 & 1.30 & $0.85-2.02$ \\
\hline No & 134 & 158 & $1.00^{\mathrm{b}}$ & \\
\hline \multicolumn{5}{|c|}{ Maternal asthma } \\
\hline Yes & 75 & 31 & $3.24^{\star \star \star}$ & $2.05-5.10$ \\
\hline No & 154 & 206 & $1.00^{\mathrm{b}}$ & \\
\hline \multicolumn{5}{|c|}{ Maternal eczema } \\
\hline Yes & 83 & 54 & $1.96^{\star * *}$ & $1.31-2.93$ \\
\hline No & 143 & 182 & $1.00^{b}$ & \\
\hline \multicolumn{5}{|c|}{ Maternal hayfever } \\
\hline Yes & 103 & 77 & $1.74^{\star *}$ & $1.20-2.54$ \\
\hline No & 122 & 159 & $1.00^{b}$ & \\
\hline \multicolumn{5}{|c|}{ Paternal asthma ${ }^{a}$} \\
\hline Yes & 56 & 23 & $3.02^{\star \star *}$ & $1.81-5.06$ \\
\hline No & 153 & 190 & $1.00^{b}$ & \\
\hline \multicolumn{5}{|c|}{ Paternal eczema ${ }^{a}$} \\
\hline Yes & 51 & 33 & $1.71^{*}$ & $1.05-2.7 \mathrm{c}$ \\
\hline No & 156 & 173 & $1.00^{b}$ & \\
\hline \multicolumn{5}{|c|}{ Paternal hayfever ${ }^{a}$} \\
\hline Yes & 95 & 64 & $1.92^{\star * \star}$ & $1.29-2.86$ \\
\hline No & 113 & 146 & $1.00^{\mathrm{b}}$ & \\
\hline
\end{tabular}

Notes:

(a) Numbers do not add up to totals because children without siblings or paternal data available were not included in defining these variables. (b) Reference category

${ }^{*} \mathrm{p}<0.05,{ }^{* *} \mathrm{p}<0.01,{ }^{* * *} \mathrm{p} \leq 0.001$
Table 4: Odds ratios and $95 \%$ confidence intervals for the association between asthma in New Zealand children and gestation, birth weight and infant diet.

\begin{tabular}{|c|c|c|c|c|}
\hline & $\begin{array}{c}\text { Cases } \\
(n=233)\end{array}$ & $\begin{array}{c}\text { Controls } \\
(n=241)\end{array}$ & OR & $95 \% \mathrm{Cl}$ \\
\hline \multicolumn{5}{|c|}{ Whether born early } \\
\hline Yes & 62 & 54 & 1.27 & $0.83-1.93$ \\
\hline No & 166 & 183 & $1.00^{\mathrm{a}}$ & \\
\hline \multicolumn{5}{|c|}{ Number of weeks early } \\
\hline 0 & 166 & 183 & $1.00^{\mathrm{a}}$ & \\
\hline 1 & 15 & 11 & 1.50 & $0.67-3.35$ \\
\hline 2 & 24 & 24 & 1.10 & $0.60-2.02$ \\
\hline 3 & 7 & 7 & 1.10 & $0.38-3.21$ \\
\hline$\geq 4$ & 16 & 12 & 1.47 & 0.68-3.19 \\
\hline \multicolumn{5}{|l|}{ Birth weight $(\mathrm{kg})$} \\
\hline$\leq 2.5$ & 15 & 16 & 0.92 & $0.44-1.92$ \\
\hline$>2.5$ and $<4$ & 179 & 176 & $1.00^{\mathrm{a}}$ & \\
\hline$\geq 4$ & 29 & 38 & 0.75 & $0.44-1.27$ \\
\hline \multicolumn{5}{|c|}{ Whether breastfed } \\
\hline Yes & 208 & 219 & 0.91 & $0.48-1.72$ \\
\hline No & 21 & 20 & $1.00^{\mathrm{a}}$ & \\
\hline \multicolumn{5}{|c|}{ Months breastfed } \\
\hline Not breastfed & 21 & 20 & $1.00^{\mathrm{a}}$ & \\
\hline$>0-4$ & 51 & 59 & 0.82 & $0.40-1.69$ \\
\hline$>4-8$ & 45 & 51 & 0.84 & $0.40-1.75$ \\
\hline$>8-12$ & 65 & 59 & 1.05 & $0.52-2.13$ \\
\hline$>12$ & 47 & 50 & 0.90 & $0.43-1.86$ \\
\hline \multicolumn{5}{|c|}{ Introduction of cow's milk } \\
\hline$<1$ year & 144 & 151 & 1.00 & $0.66-1.51$ \\
\hline$\geq 1$ year & 63 & 66 & $1.00^{\mathrm{a}}$ & \\
\hline
\end{tabular}

Note:

(a) Reference category.

asthma, and this was similar for girls $(\mathrm{OR}=10.49,95 \% \mathrm{CI} 1.76-$ 62.53 ) and boys (OR=9.11, 95\% CI 1.53-54.27) (not shown in tables).

We found little or no association between length of gestation, birth weight, breastfeeding, number of months breastfed, or the introduction of cow's milk in the first year of life (defined to exclude cow's milk-based formula) for either breastfed or formula-fed infants and asthma (see Table 4). Among asthmatic children, breastfed children were less likely to develop their first symptoms under one year of age $(\mathrm{OR}=0.37,95 \%$ CI $0.15-0.93)$.

Maternal smoking during pregnancy did not increase the risk of asthma. There was also no relationship between maternal, paternal or any smoking in the house, the number of smokers, and the number of cigarettes smoked during the first year of the child's life and asthma. For current smoking, although these same variables were associated with odds ratios greater than one, these were mostly weak and not significant. The exception was any smoking in the house currently which showed a marginally significant increased risk of asthma (OR=1.44, 95\% CI 0.99-2.09).

\section{Vaccinations}

Most vaccinations showed non-significantly elevated odds ratios for asthma when compared with children who had not had 
Table 5: Odds ratios and $95 \%$ confidence intervals for the association between asthma in New Zealand children and vaccinations.

\begin{tabular}{lrrrr}
\hline Vaccination & $\begin{array}{c}\text { Cases } \\
(\mathbf{n}=\mathbf{2 2 0})\end{array}$ & $\begin{array}{c}\text { Controls } \\
(\mathbf{n}=\mathbf{2 3 1})\end{array}$ & OR & $\mathbf{9 5 \%} \mathbf{C l}$ \\
\hline $\begin{array}{l}\text { Any DPT } \\
\text { Yes }\end{array}$ & 205 & 208 & 1.51 & $0.77-2.97$ \\
No & 15 & 23 & $1.00^{\mathrm{a}}$ & \\
\hline $\begin{array}{l}\text { Any DT or DPT } \\
\text { Yes }\end{array}$ & 207 & 212 & 1.43 & $0.69-2.96$ \\
No & 13 & 19 & $1.00^{\mathrm{a}}$ & \\
\hline Any Hepatitis B & & & & \\
Yes & 125 & 149 & 0.72 & $0.50-1.06$ \\
No & 95 & 82 & $1.00^{\mathrm{a}}$ & \\
\hline Any polio & & & & \\
Yes & 212 & 214 & 2.11 & $0.90-4.90$ \\
No & 8 & 17 & $1.00^{\mathrm{a}}$ & \\
\hline Measles or MMR & & & & \\
Yes & 194 & 192 & 1.52 & $0.89-2.58$ \\
No & 26 & 39 & $1.00^{\mathrm{a}}$ & \\
\hline MMR & & & & \\
Yes & 68 & 50 & $1.62^{*}$ & $1.06-2.47$ \\
No & 152 & 181 & $1.00^{\mathrm{a}}$ & \\
\hline BCG & & & & \\
Yes & 7 & 6 & 1.23 & $0.41-3.72$ \\
No & 213 & 225 & $1.00^{\mathrm{a}}$ & \\
\hline Note: & & & & \\
$\begin{array}{l}\text { (a) Reference category. } \\
{ }^{*} p<0.05\end{array}$ & & & & \\
\hline
\end{tabular}

that vaccination (see Table 5). The exception was MMR (measles, mumps and rubella) where the positive association was statistically significant. Hepatitis B vaccination showed a non-significant negative association with asthma. The exclusion from the analysis of data not based on records increased the association between polio and asthma, but did not change the association between hepatitis B or MMR and asthma.

Although children in social classes 1 and 2 were more likely to have received any vaccination $(\mathrm{OR}=1.56,95 \% \mathrm{CI} 0.37-6.61)$ than children in social classes 5 and 6 or children of unemployed parents, this was not significant. Children in social classes 1 and 2 were also more likely to have received DPT (diphtheria, pertussis, tetanus) ( $\mathrm{OR}=2.59,95 \% \mathrm{CI} 1.16-5.81)$, polio $(\mathrm{OR}=2.08,95 \%$ CI 0.76-5.69), $\mathrm{MMR}(\mathrm{OR}=1.77,95 \% \mathrm{CI} 0.95-3.32)$, any measles containing vaccine $(\mathrm{OR}=1.64,95 \% \mathrm{CI} 0.84-3.22)$ or both measles containing vaccines $(\mathrm{OR}=1.85,95 \% \mathrm{CI} 0.91-3.74)$. They were also slightly less likely to have had hepatitis $\mathrm{B}$ vaccination (OR=0.85, 95\% CI 0.51-1.42).

MMR was the only vaccine that first-born children were significantly more likely to have had than third or later-born children $(\mathrm{OR}=2.30,95 \%$ CI 1.36-3.89). They were also significantly more likely to have had both measles containing vaccines $(\mathrm{OR}=2.44$, 95\% CI 1.36-4.38) but only slightly more likely to have had the $\mathrm{MMR}$ vaccine and not the measles vaccine $(\mathrm{OR}=1.36,95 \% \mathrm{CI} 0.53$ 3.51).
Table 6: Adjusted ${ }^{\mathrm{a}}$ odds ratios and $95 \%$ confidence intervals for the association between asthma in New Zealand children and demographic, family history, vaccination and environmental smoke exposure.

\begin{tabular}{|c|c|c|c|c|}
\hline & $\begin{array}{l}\text { Cases } \\
(n=233)\end{array}$ & $\begin{array}{l}\text { Controls } \\
(n=241)\end{array}$ & OR & $95 \% \mathrm{Cl}$ \\
\hline \multicolumn{5}{|l|}{ Gender } \\
\hline Female & 91 & 134 & $1.00^{b}$ & \\
\hline Male & 142 & 107 & $1.81^{* *}$ & $1.17-2.81$ \\
\hline \multicolumn{5}{|l|}{ Social class } \\
\hline $1 \& 2$ & 106 & 118 & $1.00^{b}$ & \\
\hline 3 & 44 & 52 & 1.03 & $0.58-1.83$ \\
\hline 4 & 30 & 28 & 1.69 & $0.82-3.48$ \\
\hline 5\&6, unemplo & 53 & 43 & $2.32^{*}$ & $1.22-4.44$ \\
\hline \multicolumn{5}{|c|}{ Maternal asthma } \\
\hline Yes & 75 & 31 & $3.36^{\star * *}$ & $1.88-5.99$ \\
\hline No & 154 & 206 & $1.00^{\mathrm{b}}$ & \\
\hline \multicolumn{5}{|c|}{ Paternal asthmac } \\
\hline Yes & 56 & 23 & $2.67^{\star *}$ & $1.42-5.02$ \\
\hline No & 153 & 190 & $1.00^{b}$ & \\
\hline \multicolumn{5}{|c|}{ Maternal eczema } \\
\hline Yes & 83 & 54 & $1.80^{*}$ & $1.10-2.92$ \\
\hline No & 143 & 182 & $1.00^{b}$ & \\
\hline \multicolumn{5}{|c|}{ Paternal eczemac } \\
\hline Yes & 51 & 33 & 1.32 & $0.73-2.37$ \\
\hline No & 156 & 173 & $1.00^{b}$ & \\
\hline \multicolumn{5}{|c|}{ Maternal hayfever } \\
\hline Yes & 103 & 77 & 1.37 & $0.85-2.19$ \\
\hline No & 122 & 159 & $1.00^{b}$ & \\
\hline \multicolumn{5}{|c|}{ Paternal hayfeverc } \\
\hline Yes & 95 & 64 & $1.96^{* *}$ & $1.21-3.18$ \\
\hline No & 113 & 146 & $1.00^{\mathrm{b}}$ & \\
\hline \multicolumn{5}{|l|}{ Current smoking } \\
\hline Yes & 95 & 78 & 1.65 & $0.91-3.01$ \\
\hline No & 138 & 163 & $1.00^{b}$ & \\
\hline Vaccinations & $(n=220)$ & $(n=231)$ & & \\
\hline \multicolumn{5}{|l|}{ Any hepatitis B } \\
\hline Yes & 125 & 149 & 0.66 & $0.42-1.04$ \\
\hline No & 95 & 82 & $1.00^{b}$ & \\
\hline \multicolumn{5}{|l|}{ Any polio } \\
\hline Yes & 212 & 214 & 2.48 & $0.83-7.41$ \\
\hline No & 8 & 17 & $1.00^{b}$ & \\
\hline \multicolumn{5}{|l|}{ MMR } \\
\hline Yes & 68 & 50 & 1.43 & $0.85-2.41$ \\
\hline No & 152 & 181 & $1.00^{b}$ & \\
\hline
\end{tabular}

Notes:

(a) Adjusted for all variables shown in table plus family size, measles and whooping cough infection, child care use in the first year of life, sheepskin use in the first year of life, current use of a water bed or plastic sheet on mattress, age of mattress and any current smoking in house.

(b) Reference category.

(c) Numbers do not add up to totals because children without paternal data available were not included in defining this variable.

${ }^{*} p<0.05,{ }^{* *} p<0.01,{ }^{* * *} p=0.0001$

\section{Multivariate analysis}

The multivariate analysis (see Table 6) assessed the independent effects of all variables that were strongly or significantly related to asthma in the univariate analysis, including exposures 
whose associations with asthma are reported elsewhere. ${ }^{22,23}$ These included gender, social class, maternal and paternal asthma, family size, child care use in the first year of life, whooping cough and measles infection, hepatitis B, polio and MMR vaccination, sheepskin use in the first year of life, current use of a waterbed or plastic sheet on the mattress, age of mattress and any current smoking in the house. Sibling asthma, hayfever or eczema were not included in the model because information on maternal and paternal asthma, eczema and hayfever was available to allow for direct control for family history of asthma.

Having maternal or paternal asthma, maternal eczema or paternal hayfever, or being male remained significant risk factors in the multivariate analysis. Children from social classes 5 and 6 or with unemployed parents were also significantly more likely to have asthma than children in social classes 1 and 2 . The effect of current smoking in the home increased, but its significance reduced. The associations of hepatitis B and polio with asthma were virtually unchanged, compared with the univariate analysis. The significant univariate association between MMR vaccination and asthma was found to be due to confounding by the variables for measles infection and polio vaccination. To assess the influence of social class on asthma independently of birth weight and gestational age, these variables were added to the model but did not alter the social class effect. Replacing the variable for family size with the variable for birth order did not change the outcome of the model.

A further model that combined the variables for skin prick test positivity to Dermatophagoides pteronyssinus, Dermatophagoides farinae and cat with the gender variable showed a reduction in the odds ratio for male sex from 1.95 to 1.59 (95\% CI 1.06-2.38), suggesting that some of the gender difference may occur through mechanisms involving atopy to these allergens.

\section{Discussion}

\section{Demographic factors}

Many studies have found that boys are at almost twice the risk of developing asthma than girls. ${ }^{6,7}$ We found a similar effect in the univariate analysis; some of this effect was explained by atopy to dust mites and cat in the multivariate analysis. Sears et al. ${ }^{24}$ also found that gender differences for asthma reduced after adjustment for skin-test responsiveness to house dust mite and/or cat. Reasons for the residual excess prevalence among boys are unknown.

Our finding of increased asthma prevalence in lower social classes is consistent with the findings of Strachan et al., ${ }^{25}$ who found a trend towards more current wheeze in less privileged classes. The reasons why less advantaged children should have more asthma are unclear. Lower social class status may be an indicator of other factors associated with asthma such as low gestational age, ${ }^{26}$ low birth weight ${ }^{26}$ and smoking. ${ }^{27,28}$ However, adjusting for these variables did not alter the effect of social class on asthma. Another possible explanation for our findings is that the relatively small numbers of our study population in the lower social classes reflect a lower response rate in this group and our findings could be due to selection bias if the response rate was also related to disease status. In addition, it should be noted that social class may be associated with asthma exacerbations (and hence the prolongation of symptomatic periods) rather than asthma incidence. $^{29}$

\section{Family history}

A family history of asthma is also a frequently reported risk factor for asthma, which our study confirmed..$^{5,7,8,26,30}$ Fergusson, in a New Zealand cohort study, found that the association between parental asthma and asthma in four-year-old children was true for boys but not girls, and concluded that the expression of asthma in genetically susceptible female children is delayed until middle childhood compared with its earlier expression in genetically susceptible boys. ${ }^{8}$ The older age (7-9 years) of the children in our study may explain why we did not find such clear gender differences in the association between parental asthma and childhood asthma. After adjusting for possible confounders we found a greater influence of maternal versus paternal asthma on asthma in the child. This is consistent with the New Zealand study by Sears et al. ${ }^{5}$

\section{Breastfeeding}

We found no effect of breastfeeding on asthma prevalence at age 7-9. However, breastfeeding seems to delay the onset of asthma symptoms, possibly because it protects against wheezing associated with infectious respiratory illness in infancy.

\section{Parental smoking}

Although we found no effect of early life exposures to tobacco smoke on the prevalence of asthma, we have shown a marked increase in the risk of asthma $(\mathrm{OR}=1.65)$ associated with current smoking in the home. A recent review of parental smoking reported that although environmental tobacco smoke was associated with small increased risks of asthma these were important because of the large number of children exposed to smoking in the home. ${ }^{31}$ This is supported in our study where $41 \%$ of asthmatics lived with a smoker.

\section{Vaccinations}

Overall, we found little evidence of an association between vaccination and asthma; although the odds ratios for some vaccinations were non-significantly elevated, this small increased risk could be due to the method of case selection. For example, if the cases were more likely to have had access to medical care they would therefore be more likely to have been vaccinated. Furthermore, for most vaccinations, only small numbers of children were unexposed, and it is possible that some of these children did receive vaccinations that were not recorded. Thus, our findings should be considered with caution.

The significant univariate association of MMR vaccination with asthma was found to be due to confounding by measles infection and polio vaccination. Nevertheless, after adjustment, the 
association for MMR with asthma remained positive, which is consistent with a recent study of Steiner schools where children not receiving the MMR vaccination were significantly less likely to be atopic. ${ }^{32}$ Since MMR was not introduced into New Zealand until 1990 (when the children in our study were aged about 4-6 years) the uptake of this vaccination was low but higher among children of low birth order and high social class. However, adjusting for these possible confounders did not substantially reduce the effect of MMR on asthma.

Hepatitis B was also introduced as a universal vaccination in New Zealand in 1990. Our finding of a weak negative association for hepatitis B vaccination is of interest in light of the protective effect of Hepatitis A infection found by Matricardi et al. ${ }^{33}$ To confirm our findings, a study of approximately twice the size would be required.

The later universal introduction of MMR and hepatitis B vaccination meant that there were more children in the non-exposed comparison group, increasing our confidence in the results. Nevertheless, our findings for vaccinations are inconclusive, and future studies should involve a sample of all asthmatics (rather than diagnosed asthmatics) in populations that include a significant proportion of non-vaccinated children.

Finally, caution is needed in the interpretation of the study results; since we examined many factors some will be significant by chance alone.

\section{Acknowledgements}

The Wellington Asthma Research Group is funded by a program grant from the Health Research Council of New Zealand. Funding for this study was from a Health Research Council project grant and a University of Otago research grant. We would like to thank Dr Ossman Mansoor for his valuable comments on the manuscript.

\section{References}

1. Crane J, Lewis S, Slater T, Crossland L, Robson B, et al. The self-reported prevalence of asthma symptoms amongst adult New Zealanders. $N Z$ Med J 1994; 107:417-21.

2. The International Study of Asthma and Allergies in Childhood (ISAAC). Worldwide variations in the prevalence of asthma symptoms: The International Study of Asthma and Allergies in Childhood (ISAAC). Eur Respir J 1998; 12:315-35.

3. Shaw R, Crane J, O'Donnell T, Porteous L, et al. Increasing asthma prevalence in a rural New Zealand adolescent population: 1975-89. Arch Dis Child 1990;65:1319-23.

4. Mitchell E. Increasing prevalence of asthma in children. $N \mathrm{Z} \mathrm{Med} \mathrm{J}$ 1983;96:463-4.

5. Sears M, Holdaway M, Flannery E, Herbison G, et al. Parental and neonatal risk factors for atopy, airway hyper-responsiveness, and asthma. Arch Dis Child 1996;75:392-8.
6. Horwood L, Fergusson D, Shannon F. Social and familial factors in the development of early childhood asthma. Pediatrics 1985;75:859-68.

7. Shaw R, Woodman K, Crane J, Moyes C, et al. Risk factors for asthma symptoms in Kawerau children. $N$ Z Med J 1994;107:387-91.

8. Fergusson D, Horwood L, Shannon F. Parental asthma, parental eczema and asthma and eczema in early childhood. J Chron Dis 1983;36:517-24.

9. Kemp T, Pearce N, Fitzharris P, Crane J, et al. Is infant immunisation a risk factor for childhood asthma and allergy? Epidemiology 1997;8:678-80.

10. Martinez F. Role of viral infections in the inception of asthma and allergies during childhood: Could they be protective? Thorax 1994;49:1189-91.

11. Shaheen S. Changing patterns of childhood infection and the rise in allergic disease. Clin Exp Allergy 1995;25:1034-7.

12. Szentivanyi A. The beta adrenergic theory of the atopic abnormality in bronchial asthma. J Allergy 1968;42:203-32.

13. Odent M, Culpin E, Kimmel T. Pertussis vaccination and asthma: is there a link [letter]? J Am Med Assoc 1994;272:592-3.

14. Nilsson L, Kjellman N-I M, Bjorksten B. A randomized controlled trial of the effect of pertussis vaccines on atopic disease. Arch Pediatr Adolesc Med 1998;152:732-8.

15. Farooqi I, Hopkin J. Early childhood infection and atopic disorder. Thorax 1998;53:927-32.

16. Henderson J, North K, Griffiths M, Harvey I, et al. The Avon Longitudinal Study of Pregnancy and Childhood Team. Pertussis vaccination and wheezing illnesses in young children: prospective cohort study. $\mathrm{Br} \mathrm{Med} J$ 1999;318:1173-6.

17. Hurwitz E, Morgenstern H. Effects of diphtheria-tetanus-pertussis vaccination on allergies and allergy-related respiratory symptoms among children and adolescents in the United States. J Manipulative Physiol Ther 2000;23:8190 .

18. Asher M, Barry D, Clayton T, Crane J, et al. The burden of symptoms of asthma, allergic rhinoconjunctivitis and atopic eczema in children and adolescents in 6 New Zealand centres: ISAAC Phase One. $N Z$ Med J. In press 2000 .

19. Johnston R. A Revision of Socio-Economic Indices for New Zealand. Wellington: New Zealand Council for Educational Research; 1983.

20. Mantel N, Haenszel W. Statistical aspects of the analysis of data from retrospective studies of disease. J Natl Cancer Inst 1959;22:719-48.

21. Harrell F. The Logist Procedure. Cary(NC): SAS Institute; 1983.

22. Wickens K, Crane J, Kemp T, Lewis S, et al. Family size, infections and asthma prevalence in New Zealand children. Epidemiology 1999;10:699-705.

23. Wickens K, Pearce N, Siebers R, Ellis I, et al. Indoor environment, atopy and the risk of asthma in New Zealand children. Pediatr Allergy Immunol 1999; 10:199-208

24. Sears M, Burrows B, Flannery E, Herbison G, et al. Atopy in childhood. I Gender and allergen related risks for development of hayfever and asthma. Clin Exp Allergy 1993;23:941-8.

25. Strachan D, Anderson H, Limb E, O’Neill A, et al. A national survey of asthma prevalence, severity, and treatment in Great Britain. Arch Dis Child 1994; $70: 174-8$

26. Oliveti J, Kercsmar C, Redline S. Pre- and perinatal risk factors for asthma in inner city African-American children. Am J Epidemiol 1996;143:570-77.

27. Stoddard J, Miller T. Impact of parental smoking on the prevalence of wheezing respiratory illness in children. Am J Epidemiol 1995;141:96-102.

28. Martinez F, Cline M, Burrows B. Increased incidence of asthma in children of smoking mothers. Pediatrics 1992;89:21-6.

29. Pearce N, Beasley R, Burgess C, Crane J. Asthma Epidemiology: Principles and Methods. New York: Oxford University Press; 1998.

30. Infante-Rivard C. Childhood asthma and indoor environmental risk factors. Am J Epidemiol 1993;137:834-44.

31. Peat J, Li J. Reversing the trend: Reducing the prevalence of asthma. J Allergy Clin Immunol 1999;103:1-10.

32. Alm J, Swartz J, Lilja G, Scheynius A, et al. Atopy in children of families with an anthroposophic lifestyle. Lancet 1999;353:1485-88.

33. Matricardi P, Rosmini F, Ferrigno L, Nisini R, et al. Cross sectional retrospective study of prevalence of atopy among Italian military students with antibodies against hepatitis A virus. Br Med $J$ 1997;314:999-1003. 